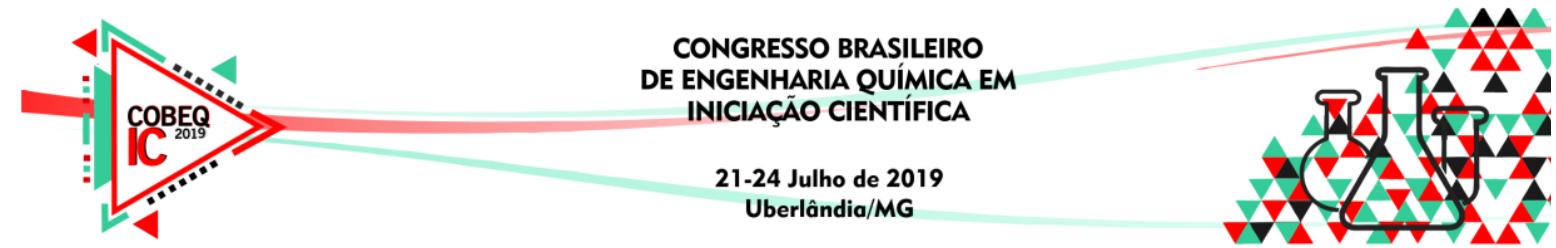

\title{
INFLUÊNCIA DA ETAPA DE CHAPTALIZAÇÃO SOBRE O PERFIL SENSORIAL DO FERMENTADO DA ACEROLA
}

\author{
A. F. de SOUSA ${ }^{1}$, W. B. P. NEVES ${ }^{2}$, M. N. MORAIS ${ }^{3}$, S. K. S. CARMO ${ }^{4}$, L. M. de \\ HOLANDA JUNIOR $^{5}$
}

${ }^{1}$ Universidade Federal Rural do Semi-Árido, Departamento de Engenharia Civil

${ }^{2}$ Universidade Federal de Rural do Semi-Árido, Departamento de Ciência e Tecnologia 3,4,5 Universidade Federal Rural do Semi-Árido, Departamento de Ciências Exatas e Naturais

E-mail para contato: waleskhacml@outlook.com

\begin{abstract}
RESUMO - Assim como a uva, diversas outras frutas podem ser submetidas ao processo de fermentação. Durante esse processo o agente atuante, Saccharomyces cerevisiae, é submetido a fatores estressantes os quais alteram o seu metabolismo e qualidade do produto final na fermentação. Dentre tais fatores há a concentração de substrato (açúcar), que em maior ou menores quantidades podem ocasionar modificações sobre o produto final desejado. O trabalho teve como objetivo investigar a influência desse substrato em diferentes concentrações na fermentação do mosto de acerola. A análise de açúcares redutores totais (ART) possibilitou a identificação dos tipos de fermentados produzidos, com isso, tivemos um fermentado do tipo seco e semi-seco. A partir da análise sensorial, aplicada aos produtos obtidos por meio dos testes, observou-se que houve a predominância pela escolha da fermentação tipo 2, fato que se deu devido ao seu processo de fermentação.
\end{abstract}

\section{INTRODUÇÃO}

A fermentação alcoólica é considerada a principal etapa para a obtenção do álcool, ela ocorre de forma anaeróbia. $\mathrm{O}$ processo ocorre na presença de micro-organismos, conhecidos como leveduras, as quais auxiliam na conversão de açúcares em etanol $\left(\mathrm{C}_{2} \mathrm{H}_{6} \mathrm{O}\right)$ e gás carbônico $\left(\mathrm{CO}_{2}\right)$ (FILHO, 2016). Na indústria biotecnólogica o gênero Saccharomyces cerevisiae se apresenta como a espécie mais explorada comercialmente para o uso na fermentação (DOS SANTOS, GUSMÃO e GOUVEIA, 2010).

Durante a fermentação, a levedura pode ser exposta a diversos fatores. Esses fatores em questão, influenciam no seu crescimento e comportamento metabólico, podendo ser citados: temperatura, $\mathrm{pH}$, concentração inicial de células e concentração inicial de substrato (açúcar) (HENRIQUE, SILVA E PINHEIRO, 2014). Além disso, a utilização de valores que não correspondem ao ideal afeta a eficiência da conversão de substrato em produto, isto é, o rendimento da fermentação.

Nos processos fermentativos, a presença de açúcar no meio é fundamental para que haja a conversão em etanol, pois ao decorrer da fermentação boa parte dessa concentração é destinada à produção de álcool. Algumas frutas por si só, já apresentam uma quantidade de 


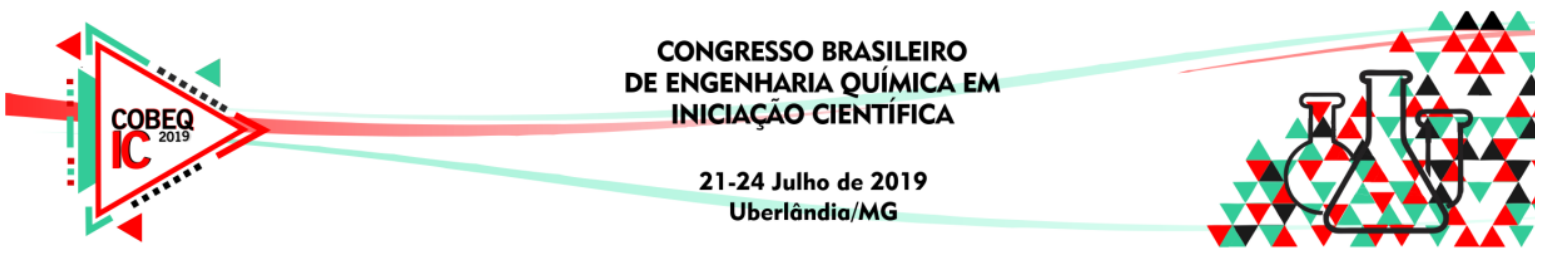

açucares satisfatória a conversão em $\mathrm{C}_{2} \mathrm{H}_{6} \mathrm{O}$, porém outras, se faz necessário a adição de uma quantidade extra, como forma de obter um produto final com teor alcoólico dentro dos padrões exigidos por legislação para ser considerado como fermentado. Uma das etapas que precede a fermentação propriamente dita é a chaptalização, a qual consiste no acréscimo de açúcar no meio a fim de aumentar a quantidade total de açúcar e assim elevar o potencial de teor alcoólico.

Conforme Cerqueira (2013) altas concentrações de açúcar ocasionam o estresse osmótico e o estresse alcoólico devido ao elevado teor de etanol no final da fermentação. De acordo com o modelo de Monod, conforme citado por Henrique, Silva e Pinheiro (2014), o aumento de substrato exibe uma cinética de crescimento celular do tipo saturação, o que leva a inativação das enzimas. Quando a concentração ultrapassa 150 g.L $\mathrm{L}^{-1}$, há ocorrência do efeito inibidor por parte do substrato (HENRIQUE, SILVA E PINHEIRO, 2014)

Por se tratar de organismos vivos, estes necessitam de fontes de nutrientes, tais como fontes de carbono (açúcares), vitaminas, nitrogênio, fósforo, magnésio, ferro e outros elementos. Muitos dos nutrientes podem estar presentes no mosto, sendo desnecessária sua adição (SANTOS, 2008). Por apresentar tais requisitos a acerola (Malpighia emarginata) apresenta-se como insumo para a via fermentativa. Além de, a partir do seu processamento gerar um produto de valor agregado, seu uso também se caracteriza como alternativa de aproveitamento do fruto desperdiçado em seu período de pós colheita. Nesse sentido, o presente trabalho teve como objetivo investigar a influência de diferentes concentrações iniciais de substrato e seus feitos inibitórios sobre a eficiência na elaboração de fermentado alcoólico do suco extraído da acerola.

\section{MATERIAIS E METÓDOS}

\subsection{Obtenção do fruto, seleção e extração do suco}

A matéria prima - Acerola (Malpighia emarginata) foi adquirida no Sítio Desterro de Portalegre/RN. Após a seleção e higienização das frutas, procedeu-se a extração do suco e a medição de parâmetros físico-químicos.

\subsection{Clarificação}

A clarificação consistiu da etapa de retirada da pectina contida no mosto, a qual pode dar origem ao metanol durante a fermentação, tornando a bebida imprópria ao consumo. Nesta, houve a adição de uma solução de gelatina $10 \%$ (comercial, incolor e inodora) como clarificante, na fração de $3 \mathrm{~g} /$ litro de suco. $\mathrm{O}$ mosto foi deixado por um período de $24 \mathrm{~h}$ à $18^{\circ} \mathrm{C}$. Em seguida foi realizada a filtração.

\subsection{Chaptalização}

Para o estudo da influência da concentração inicial de substrato e com a finalidade de adequar as condições do mosto para a fermentação, procedeu-se com a adição de sacarose. $\mathrm{O}$ mosto foi dividido em duas partes iguais de 3L, fermentação 1 e fermentação 2, às quais foram adicionadas quantidades, respectivamente, $590 \mathrm{~g}$ e $350 \mathrm{~g}$ de açúcar. A concentração inicial de 


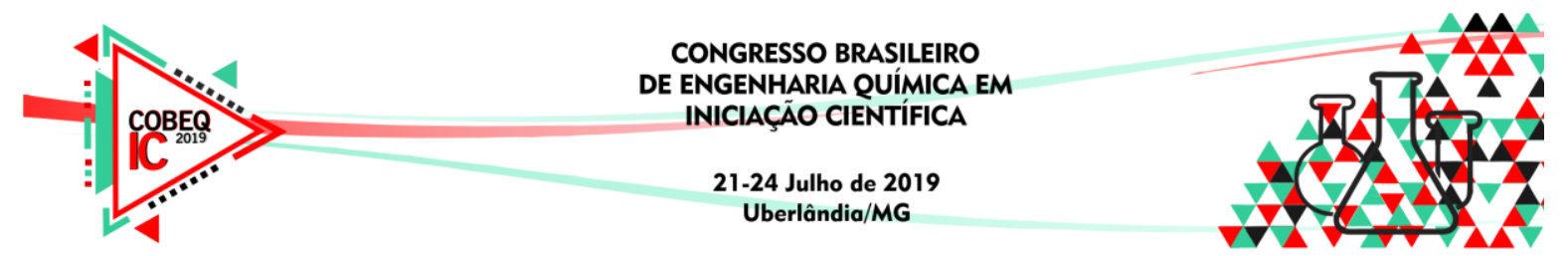

açúcar adequada foi calculada apenas para a fermentação 1 , o que correspondeu a proporção de 190 (g/L). Sendo a assim, a fermentação 2 teve a quantidade de substrato pré-definida, em quantidade inferior, na proporção de $116,7(\mathrm{~g} / \mathrm{L})$. 2:

Para mensurar as concentrações de substrato a ser adicionada, utilizou-se as equações $1 \mathrm{e}$

$$
\begin{gathered}
\operatorname{SACAROSE}(\mathrm{g} / \mathrm{L})=\left({ }^{\circ} \operatorname{BRIX} \operatorname{LIDO} X 10,13\right)+1,445 \\
\text { Açúcar a adicionar }=(220-\operatorname{SACAROSE}) \times(\text { qtde de litros do mosto })
\end{gathered}
$$

\subsection{Fermentação}

A levedura utilizada no processo é da linha Saccharomyces cerevisiae (Levedura seca ativa Blastosel Horizon). A taxa de inóculo a ser inserida no mosto correspondeu a fração de 25g/100L.Assim, as concentrações inseridas no mosto em questão foram de 6 e 3 de leveduras acondicionados em dois reatores do tipo batelada.

$\mathrm{O}$ processo de fermentação alcoólica ocorreu à temperatura $18^{\circ} \mathrm{C}$, sendo monitorados, diariamente, durante uma semana, pela medição residual do ${ }^{\circ}$ Brix até a sua estabilização, bem como $\mathrm{pH}$ e acidez. $\mathrm{O} \mathrm{pH}$ foi verificado no momento que antecedeu a fermentação e ao final, conforme a metodologia analítica do instituto Adolfo Lutz (2008). A quantidade de levedura introduzida ao mosto foi realizada de acordo com o especificado, $25 \mathrm{~g} / 100 \mathrm{~L}$ de mosto.

\section{RESULTADOS E DISCUSSÃO}

Após a seleção e higienização das frutas, procedeu-se a extração do suco e a medição dos parâmetros físico-químicos: $\mathrm{pH}$, acidez e gravidade específica ( ${ }^{\circ}$ Brix), a fim de definir as condições iniciais para a fermentação alcoólica. Através das análises, foi observado, como mostra a Tabela 1, os valores de caracterização para as variáveis em questão.

4. Tabela 1 - Caracterização físico-química da acerola 5.

\begin{tabular}{|c|c|c|c|}
\hline Parâmetro & $\mathbf{p H}$ & Gravidade especifica $\left({ }^{\circ}\right.$ Brix $)$ & Acidez $(\mathbf{g} / \mathbf{1 0 0 m})$ \\
\hline Valores & 3,61 & 2,8 & 0,306 \\
\hline
\end{tabular}

Durante a fermentação, foi realizada a cinética fermentativa sobre os fermentados 1 e 2 , para avaliar a influência do chaptalização, sobre as variáveis do processo. Como mostra a Figura 1 , os perfis de decaimento de substrato versus o crescimento da produção de etanol ambos em $(\mathrm{g} / \mathrm{L})$. Comparando-se as duas fermentações (Figura 1) percebe-se que há um aumento considerável na curva do Brix nas primeiras $24 \mathrm{~h}$, onde ambas demonstram um decaimento logo em seguida.

No entanto, observa-se que na fermentação referente ao meio com $190 \mathrm{~g} / \mathrm{L}$ de substrato inicial o ${ }^{\circ}$ Brix se estabiliza em torno de 5.9, cujo valor denota que nem todo açúcar foi 


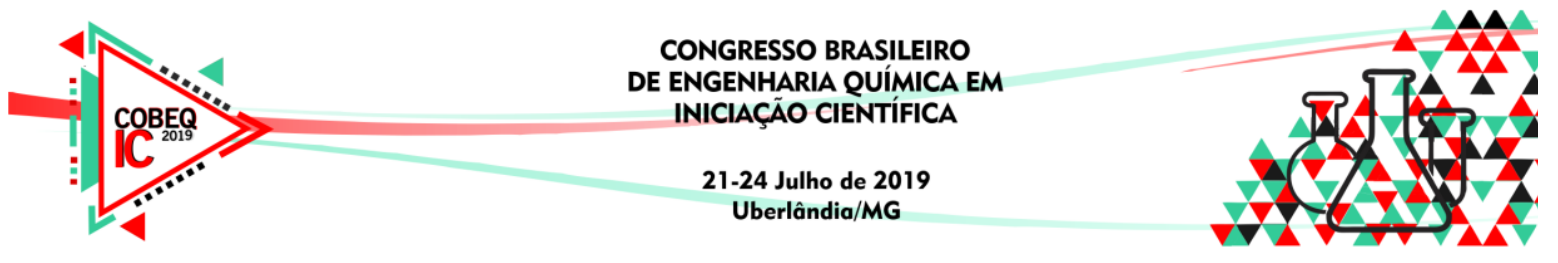

convertido em álcool durante o processo, o que pode ser justificado pela quantidade de açúcar superior a $150 \mathrm{~g} \cdot \mathrm{L}^{-1}$.

Por simetria, ao analisar o segundo ensaio fermentativo, percebe-se o ${ }^{\circ}$ Brix se estabiliza com 3,9 , o que demonstra que neste caso o processo de conversão de substrato em produto foi mais eficiente.

Figura 1 - Cinética fermentativa da produção do Fermentado 1 e 2, respectivamente
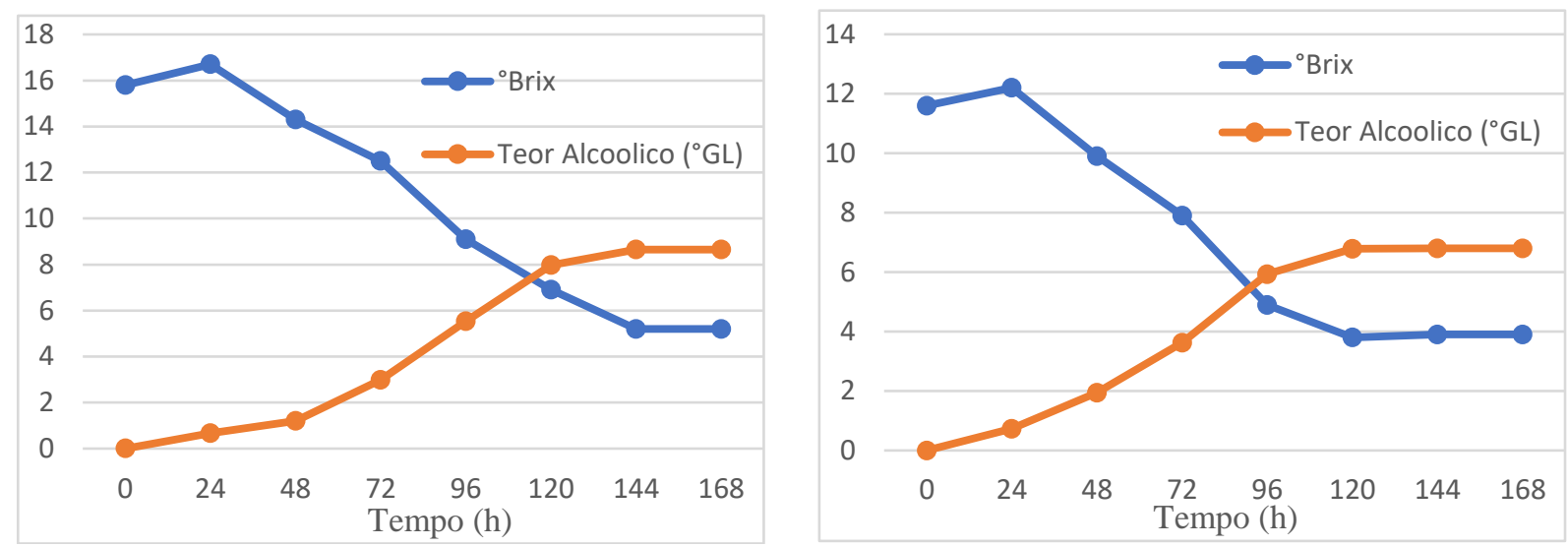

Os parâmetros analisados demonstram que no ensaio fermentativo 1, a fermentação ocorreu satisfatoriamente até às 144 horas, após isso observa-se um decaimento acentuado até a sua estabilização. Esse resultado mostra que provavelmente o processo foi inibido ou sofreu retardo devido algum fator presente no processo, podendo estar intimamente ligado ao excesso de sacarose. Essa análise decorre do fato que com o valor inicial de $\mathrm{pH}$ presente no mosto, o favorecimento de bactérias infecciosas pode não ocorrer, pois é justamente nessa faixa que há um bom desenvolvimento da levedura (AMORIM, 2005).

O rendimento da fermentação foi calculado através da quantidade de litros produzidos o qual equivaleu a 1,5L da bebida, pela quantidade de litros correspondente ao mosto. Em seguida para expressar tal valor em porcentagem multiplicou-se o valor por cem. Assim, o rendimento médio de ambas as fermentações foi de $50 \%$.

Nesse sentido, infere-se que a quantidade de açúcar adicionada a mais na fermentação 1 , não está em concordância com o valor encontrado no estudo feito por Henrique, Silva e Pinheiro (2014) onde percebeu-se que a uma concentração de $180 \mathrm{~g} / \mathrm{L}$ a levedura sofreu inibição, onde o rendimento obtido foi de $88,62 \%$, ficando assim comprometida a conversão de açúcares em produto. Dentre as diversas classificações atribuídas ao fermentado, tem-se como base a classificação de açúcar presente em $\mathrm{g} / \mathrm{L}$, cuja finalidade é a verificação dos açúcares convertidos em etanol durante o processo fermentativo (NEVES, 2018).

O fermentado 1 obteve uma concentração final de ART equivalente a 4,27 g/L. Já o produto obtido por meio da fermentação 2 estabilizou-se ao fim do processo em uma quantidade de $8,77 \mathrm{~g} / \mathrm{L}$. Os fermentados se classificam como tipo seco e meio seco, respectivamente, conforme determina o Decreto do Vinho (1988). Em seguida, como forma de avaliar o produto obtido através da pesquisa, realizou-se a avaliação sensorial. Para tal análise, foram 


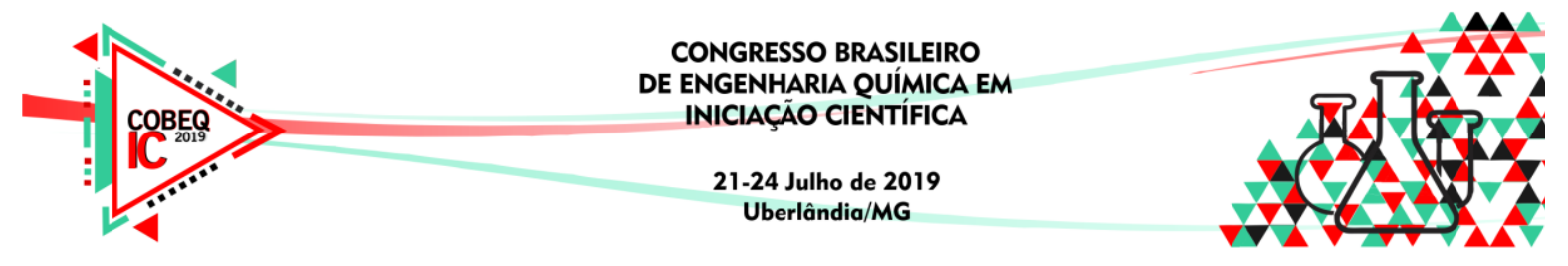

selecionados, de forma aleatória, 10 pessoas. Onde no primeiro questionamento os provadores analisaram o sabor e o aroma da amostra 1 e 2, conforme é possível observar nas Figuras 1, 2, 3,4 .

Figura 2 -Análise do sabor do fermentado 1

Figura 3 - Análise do aroma do fermentado 1
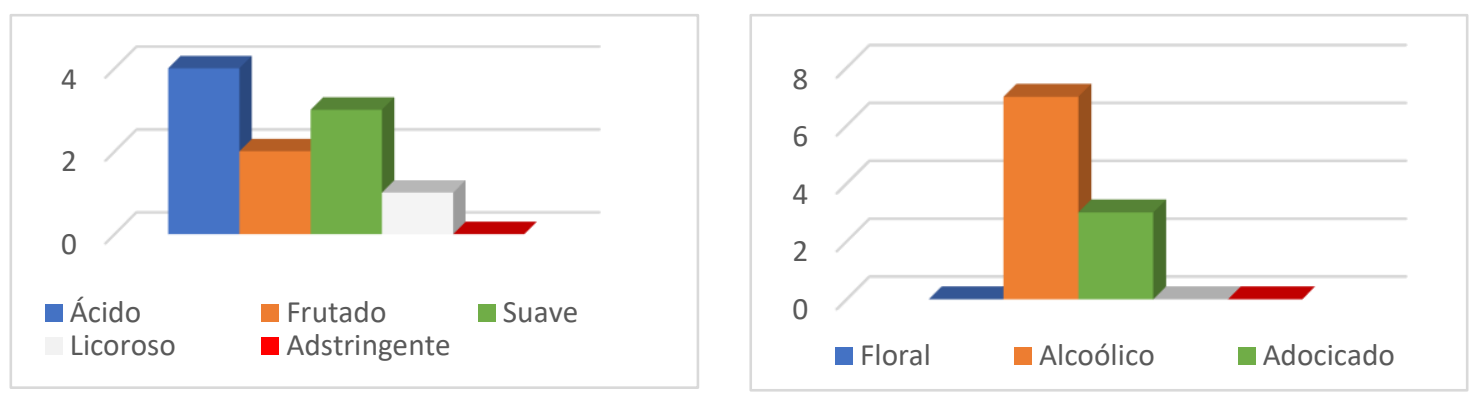

Figura 4 -Análise do sabor do fermentado 2 Figura 5 - Análise do aroma do fermentado 2
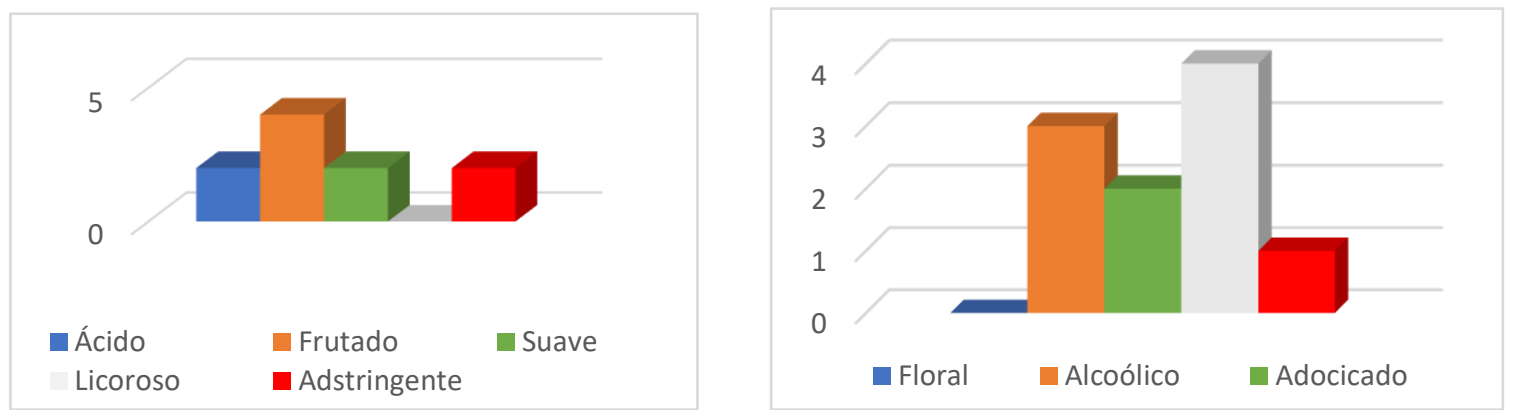

Na Figura 1 nitidamente percebe-se a prevalência da escolha pelo sabor ácido, o que pode ter sido ocasionado pela inativação da levedura, e formação de produtos indesejados durante a fermentação. Já na Figura 3 observa-se que há uma predominância na escolha dos avaliadores pelo sabor frutado, denotando que a característica da fruta foi conservada durante o processo. Além disso, na Figura 4 também ressalta outra característica intrínseca da fruta, visto que a predominância se deu no aroma frutado.

Por fim, foi realizado o questionamento sobre a avaliação geral dos fermentados, onde foi realizado a média entre um público de 10 provadores. $\mathrm{O}$ fermentado 1 apresentou média de aceitação de 8,1, ao passo que a fermentação 2 apresentou maior valor, com média de 8,6. Em análise, percebe-se a preferência pelo fermentado do tipo 2 por possuir maiores características da fruta foi a mais aceita pelo público.

\section{CONCLUSÃO}

Durante a pesquisa observou-se que uma quantidade inferior, ao tido como ideal para o processo fermentativo, de açúcar, adicionada na etapa da chaptalização, mostrou-se suficiente para o desenvolvimento satisfatório da fermentação. Esta evidência foi comprovada através do teste de aceitação do produto. A bebida obtida, caracterizou-se como fermentado do tipo semiseco, e no quesito avaliado sobre a aceitação global, obteve-se uma maior preferência. Apesar 


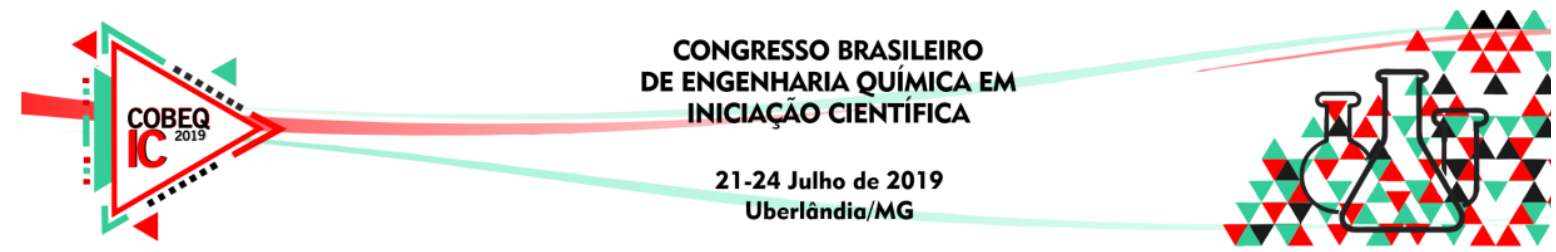

do fermentado tipo 1, realizado com a quantidade ideal indicada de açúcar, por meio dos cálculos, ter proporcionado a obtenção de um produto com teor alcoólico superior, outros subprodutos indesejados podem também ter sido gerados no processo, tornando assim, o produto não tão agradável quanto o obtido na fermentação 2.

\section{REFERÊNCIAS}

AMORIM, H. V. Fermentação alcoólica, ciência \& tecnologia. Piracicaba: Fermentec, 2005. $448 p$.

CERQUEIRA, D. P. Fermentação alcoólica de mosto com alta concentração de açúcar. 2013. 67 f. Dissertação (Mestrado) - Curso de Ciência e Tecnologia de Alimentos, Universidade de São Paulo, Piracicaba, 2013.

DECRETO DO VINHO - Decreto n. 99.066/1990 - Regulamenta a Lei n. ${ }^{\circ} 7.678$, de 8 de novembro de 1988, que dispõe sobre a produção, circulação e comercialização do vinho e derivados do vinho e da uva. Disponível em: Acesso em 17 de março de 2019.

DOS SANTOS, J. R. A.; GUSMÃO, N. B.; GOUVEIA, E. R. Seleção de linhagem industrial de Saccharomyces cerevisiae com potencial desempenho para produção de etanol em condições adversas de temperatura e de agitação. Revista Brasileira de Produtos Agroindustriais, v.12, n.1, pp.75-80, 2010.

FILHO, W.G.V. (Coord.). Bebidas alcoólica: Ciência e Tecnologia. - 2. ed. - São Paulo: Blucher, 2016.

HENRIQUE, J. M.; SILVA, N. C. G.; PINHEIRO, A. D. T.; Influência da concentração inicial de açúcar na fermentação alcoólica do suco de melão, p. 43-48. In: Anais do XX Congresso Brasileiro de Engenharia Química - COBEQ 2014 [= Blucher Chemical Engineering Proceedings, v.1, n.2]. São Paulo: Blucher, 2015.

INSTITUTO ADOLFO LUTZ (São Paulo). Métodos físico-químicos para análise de alimentos. ed. 4. São Paulo: Instituto Adolfo Lutz, p. 1020, 2008.

NEVES, W. B. P. Produção, caracterização físico-química e análise de fermentados de caju por técnicas distintas. 2018. 58f. TCC (Graduação) - Curso de Ciência e Tecnologia, Centro Multidisciplinar de Ciências Exatas, Universidade Federal Rural do Semiárido, Pau do Ferros, 2018.

STEINLE, L. A. Fatores que interferem na fermentação alcoólica. 2013. 58 f. Monografia (Especialização) - Curso de Gestão Industrial Sucroenergética, Centro de Ciências Agrárias, Universidade Federal de São Carlos, Sertãozinho, 2013.

SANTOS, A. M. dos. Estudo da influência da complementação de Nutrientes no mosto sobre o processo de fermentação alcoólica em batelada. 2008. 95 f. Dissertação (Mestrado) - Curso de Engenharia Química, Centro de Ciências Exatas, Universidade Federal de Alagoas, Maceió, 2008. 